\title{
Atamalcualiztli ou à la recherche du tamoanchan perdu essai d'interprétation d'une fête religieuse des anciens mexicains
}

Patrick Saurin

\author{
CpenEdition \\ Journals \\ Édition électronique \\ URL : http://journals.openedition.org/assr/23222 \\ DOI : $10.4000 /$ assr.23222 \\ ISSN : $1777-5825$ \\ Éditeur \\ Éditions de l'EHESS
}

Édition imprimée

Date de publication : 1 juillet 2002

ISBN : 2-222-96721-X

ISSN : 0335-5985

\section{Référence électronique}

Patrick Saurin, «Atamalcualiztli ou à la recherche du tamoanchan perdu essai d'interprétation d'une fête religieuse des anciens mexicains ", Archives de sciences sociales des religions [En ligne], 119 | juillet - septembre 2002, mis en ligne le 05 septembre 2011, consulté le 20 avril 2019. URL : http:// journals.openedition.org/assr/23222 ; DOI : 10.4000/assr.23222 
Arch. de Sc. soc. des Rel., 2002, 119, (juillet-septembre 2002) 147-168

Patrick SAURIN

\section{ATAMALCUALIZTLI \\ OU À LA RECHERCHE DU TAMOANCHAN PERDU ESSAI D'INTERPRÉTATION D'UNE FÊTE RELIGIEUSE DES ANCIENS MEXICAINS*}

Parmi les traits partagés par les diverses sociétés de l'ancienne Mésoamérique, figure en toute première place l'utilisation de différents systèmes chronologiques fonctionnant simultanément. Ainsi, à Mexico-Tenochtitlan, à l'arrivée des Espagnols au début du XVI ${ }^{\mathrm{e}}$ siècle, les prêtres mexicas avaient trois computs à leur disposition.

Tout d'abord, l'année solaire était divisée en dix-huit mois de vingt jours, chacun de ces mois donnant lieu à des cérémonies minutieusement organisées. Au terme du dernier mois de l'année, prenaient place cinq jours néfastes. Ensuite, le tonalpohualli, le "compte des destins", était un calendrier divinatoire de 260 jours composé de vingt treizaines combinant un chiffre compris entre 1 et 13 et un signe choisi dans une série de vingt. Enfin, les Mexica suivaient les révolutions synodiques de la planète Vénus. L'année vénusienne comptant 584 jours, les trois calendriers concordaient exactement au terme de 104 ans, soit 104 années solaires, 146 années divinatoires et 65 années vénusiennes. Cette période de 104 ans était appelée en langue nahuatl ce ueuetiliztli, "une vieillesse". Mais, en plus de cette coïncidence, le calendrier solaire et le calendrier vénusien voyaient leurs cycles respectifs recommencer en même temps tous les huit ans, puisque huit années solaires correspondent exactement à cinq années vénusiennes.

Or, tous les huit ans, les Mexicains célébraient une fête appelée Atamalcualiztli, "manger des tamales (1) à l'eau". C'est à cette étonnante cérémonie que nous allons nous intéresser.

Les sources sont peu prolixes sur cet événement, qui plus est, elles ne se recoupent pas complètement. Nous nous proposons de reconstituer, à partir de ces éléments épars et incomplets, la réalité et la signification de cette fête. Il est bon de préciser ici que nous avons essentiellement utilisé dans notre approche des témoi-

* À la mémoire de Marie Sautron.

(1) Les tamalli ou tamales étaient des galettes de maïs de forme ronde cuites à l'eau. 
gnages en langue nahuatl, recueillis par les religieux espagnols auprès des populations autochtones aussitôt après la conquête. Parmi ces écrits, figure un texte essentiel recueilli par le franciscain Fray Bernardino de Sahagún. Il s'agit d'un hymne sacré qui était chanté précisément tous les huit ans, lors de la fête Atamalcualiztli (2). Nous nous sommes référé également à des manuscrits pictographiques, les Codex Telleriano-Remensis et Vaticanus A notamment, lesquels, bien que réalisés durant de la seconde moitié du $\mathrm{XVI}^{\mathrm{e}}$ siècle, sont probablement les copies d'originaux aujourd'hui disparus. La mise en relation de ces différentes sources nous a permis de reconstituer la réalité d'Atamalcualiztli. Ainsi, nos investigations nous feront remonter progressivement du jeûne observé par les hommes sur terre durant cette fête en vue de régénérer le maïs, jusqu'à un lieu mythique, le Tamoanchan, une sorte de paradis originel où nous surprendrons la déesse Ixnextli transgresser un interdit sexuel. Cette rupture, à l'origine de la naissance du Dieu Maïs, nous conduira ensuite dans une contrée à l'opposé du Tamoanchan, l'inframonde. Là, dans cet univers nocturne et inquiétant, nous assisterons à une étonnante partie de jeu de balle ayant pour enjeu la naissance du Dieu Maïs.

\section{Atamalcualiztli ou la régénération des subsistances}

La plupart des témoignages assimilent cette fête à une période d'abstinence. Un extrait de la Relación de Texcoco de Pomar relate la chose suivante :

«Le jeûne général se déroulait tous les huit ans et (ne durait) pas plus de quatre jours, au cours desquels ils ne mangeaient pas de viande mais des tamales de maïs cuites, des haricots sans sel et rien d'autre, et ils ne buvaient pas d'autre breuvage que de l'eau pure. Ces tamales ne diffèrent des tortillas que par le fait qu'elles ont la forme de boules et sont cuites dans de l'eau seule. Ils plaçaient dans les maisons royales et les temples certains joncs qui signifiaient le jeûne. Je ne pus savoir pourquoi cela se faisait, seulement que cela fut introduit il y a très longtemps par les gens de Culhuacan, et sans que l'on punisse celui qui le rompait.» (Pomar, Zurita, 1941, pp. 22-23)

Si l'on en croit les informateurs mexicains du franciscain Sahagún, cette fête correspondait à une période de jeûne pendant laquelle la nourriture, épuisée par son utilisation quotidienne, reprenait les forces nécessaires à son renouvellement :

Auh inic mochivaya y quilmach yn monecivihia in tonacayutl in chicuxiuhtica, ipampa quilmach cenca tictlayhioviltia, inic tiqua in ticchilhvia intiquiztavia intictequixqujvia, in motexvia yniuhqujma ticotzon mjctia inic ticnemjtia quilmach icmopilquixtitivia, in tonacayutl, iuhqui yn muchioya. Auh iniquac otzonquiz ilhuitl, y moztlayoc motenevaya molpalolo, yehica $i$ oneçavililoc yn tonacayutl. (Sahagún, 1905 PM: $253 \mathrm{v}^{\circ}$ )

«Et on raconte qu'on faisait cela pour que la nourriture vienne se reposer tous les huit ans, parce qu'on raconte que nous la fatiguons beaucoup quand nous la mangeons, quand nous l'assaisonnons avec du piment, quand nous la salons, quand nous la faisons

(2) Les différents états du travail de ce religieux sont consignés dans les recueils connus sous les noms de: Primeros Memoriales, Codex du Palais Royal de Madrid, Codex de l'Académie Royale d'Histoire de Madrid, Manuscrit de Tolosa et Codex de Florence. Nous nous référerons essentiellement dans ce travail au premier manuscrit précité, signalé en note par l'abréviation $P M$. 
cuire, quand on lui jette de la chaux dessus, de telle sorte que nous dépassions la mesure en la maltraitant, quand nous nous en servions ainsi; on raconte qu'on faisait cela pour que la nourriture rajeunisse. Et quand finissait la fête, le jour qui suivait s'appelait "on mange les plats avec la sauce", parce que le deuil de la nourriture avait été porté.»

La chaux utilisée lors de la cuisson blanchissait le maïs, le vieillissait, à l'image d'un ancien qui prend des cheveux blancs avec l'âge. Fatiguée, usée, maltraitée par les hommes, la nourriture - le maïs - devait se reposer ou se refroidir, car les Nahua associaient la chaleur à la fatigue et le froid au repos (3).

Ces périodes de huit années, rythmant un renouvellement, une régénération, devaient donner lieu à d'autres manifestations que le jeûne observé pendant la fête car Durán nous informe que le temple de Mixcoatl (4) était rénové et réédifié tous les huit ans (5) (Durán, 1967 : I, p. 77). Il est intéressant de relever chez les Maya le lien existant entre le maïs et le chiffre huit ( $c f$. en particulier Taube, 1985, pp. 171, 173-174, et 1989, pp. 35-36, 45).

\section{Atamalcualiztli : une fête en souvenir de la faute originelle commise par Ixnextli au Tamoanchan}

La fête Atamalcualiztli portait d'autres dénominations qui vont nous éclairer davantage sur son sens profond. Il existe dans le Codex de Madrid un passage fort intéressant, repris par Sahagún dans la Historia General, mais avec une traduction que nous croyons défectueuse. En effet, le franciscain écrit dans cet ouvrage : "Ils appelaient cette fête ixnextiua, ce qui signifie chercher la fortune" (Sahagún, 1975, p. 157). Or le passage original correspondant des Primeros Memoriales à partir duquel la version en espagnol de l'Historia General a été élaborée donne le texte nahuatl suivant: Auh iniquac ilhuitl quiçaya moteneoa ixnextioaya: ioan ixtecocoltioaya (Sahagún, 1905 PM: $253 \mathrm{v}^{0}$ ), ce que l'on peut traduire par : "Et quand la fête arrivait, on l'appelait on a de la cendre sur le visage, et aussi on a du charbon sur le visage" (c'est nous qui soulignons) (6). Ixnextioa ou ixnextiua signifie quelque chose comme "se mettre à avoir de la cendre sur le visage".

(3) Ainsi que l'a observé Alfredo López Austin, dans la langue nahuatl "se reposer" et "refroidir le chaud" se disaient cehuia (nino) et cehuia (nite)" (1980, I, 292).

(4) Mixcoatl, littéralement "Serpent de nuages", était le dieu de la chasse mais comme son nom l'indique il représentait également la Voie Lactée.

(5) Nous savons que la fête Atamalcualiztli survenait au cours du mois Quecholli ou du mois Tepeilhuitl. Or, le dieu Mixcoatl était célébré lors du mois Quecholli. Des tamales étaient offertes lors de ce même mois. Au vu de ces éléments, il est possible d'avancer que la rénovation du Temple de Mixcoatl, réalisée tous les huit ans, était en relation avec la célébration d'Atamalcualiztli.

(6) La confusion de Sahagún tient au fait que celui-ci a construit sa traduction sur le verbe ixnextia que SIMÉon traduit par "amasser, se procurer une chose, acquérir du bien, de la fortune, être adroit, habile" (1963, p. 196). Or le verbe qui nous occupe est différent puisqu'il s'agit d'ixnextiua, construit non sur le mot neci, mais sur nextli, "la cendre". Ixnextiuaya se décompose comme suit: $i x(t l i)$-nex(tli)-ti-ua-ya: yeux/cendre/suffixe de dérivation verbale dénominative/suffixe impersonnel/suffixe d'imparfait. 
L'autre verbe du passage des Primeros Memoriales qui nous occupe, ixtecocoltiua, est un synonyme de ixnextiua. L'association d'un couple de propositions similaires dans une même expression est un procédé rhétorique cher aux anciens Mexicains connu sous le nom de «parallélisme». Le verbe ixtecocoltiua est construit sur le substantif tecolli, "charbon". S'il est vrai que les commentateurs qui nous ont précédé dans l'analyse de ce chant n'ont pas dirigé leur analyse sur cette voie (7), nous pensons ne pas faire fausse route, car nous avons trouvé dans plusieurs sources des éléments qui viennent à l'appui de notre démonstration ainsi que nous allons le vérifier. Si l'on sait que le fait de s'enduire le visage de cendre était chez les anciens Mexicains un signe de pénitence, il convient de s'interroger sur les raisons de la pénitence accomplie durant la fête Atamalcualiztli. La réponse à cette question se trouve dans un événement qui, selon le mythe, se serait produit au Tamoanchan, une sorte de paradis originel. En effet, selon la tradition, c'est au Tamoanchan que fut commise une faute irréparable qui eut pour conséquence de voir les dieux expulsés sur la terre et dans l'inframonde. Dans le commentaire du Codex Telleriano-Remensis, la coupable a pour nom Ixnextli (8) :

«Ils la représentaient... toujours en train de pleurer... Elle s'appelait Ixnextli, ce qui signifie les yeux couverts de cendre, et ce depuis qu'elle pécha en cueillant les fleurs, et ainsi ils disent qu'aujourd'hui ils ne peuvent regarder au ciel en souvenir de cette félicité qu'ils perdirent, ils jeûnaient tous les huit ans pour cette chute.» (Códice Telleriano-Remensis, 1964-1967 : pl. VII)

Nous retrouvons cette même histoire dans le Codex Vaticanus A :

«Ils l'appelaient Ixnextli... celle qui pleure tout le temps et se met de la cendre sur les yeux, avec une fleur à la main, pour faire comprendre qu'elle pleure de l'avoir cueillie. Et pour cela ils disaient qu'ils ne pouvaient regarder au ciel; au contraire, en souvenir du repos qu'ils avaient perdu, tous les huit ans, (ils jeûnaient) pour ce malheur, et leur jeûne était fait de pain et d'eau.» (Códice Vaticanus A, 1964-1967 : pl. XXII)

En plus de ces deux témoignages, il existe dans le manuscrit des Primeros Memoriales des informateurs de Sahagún, en regard du texte relatant la fête Atamalcualiztli, une vignette en couleurs (cf. illustration 1) sur laquelle on voit la déesse Xochiquetzal en train de tisser sur son métier relié à l'arbre fleuri du Tamoanchan, tandis que de l'autre côté de l'arbre, lui faisant face, se dresse le dieu Tezcatlipoca (9) tenant son miroir à la main (ibid. : fol. $254 \mathrm{r}^{\mathrm{o}}$ ). Ce dessin nous

(7) Relevons à ce propos que Sahagún n'a pas été la seule "victime" de cette expression particulièrement délicate à comprendre car, après lui, d'autres nahuatlatoque confirmés se sont fourvoyés dans leur traduction. Ainsi, à la suite du franciscain, GARIBAY, même s'il a rendu correctement le sens de Ixnextiuaya par "on se couvre le visage de cendre" (sans toutefois y voir le lien avec la faute commise par Ixnextli au Tamoanchan), a fait une erreur de paléographie en transcrivant atecocoltioaya au lieu de ixtecocoltioaya qu'il a traduit par "on danse comme un serpent d'eau" (1948, p. 318). DibBLE et ANDERSON l'ont imité dans cette erreur de transcription, "ixtecocoltioaya" devenant "des coquillages d'escargots sont posés" (1981, p. 177). Ils ont en outre suivi Sahagún en rendant "ixnextioaya" par "on cherche le bonheur" (ibid.). Enfin, Thelma Sullivan s'est également fourvoyée dans la traduction de ces deux verbes en proposant "on amasse la fortune" et "on se transforme en coquillages marins" (SAHAGúN, 1997, p. 68).

(8) Ixnextli, "Visage de cendre", est une divinité rarement mentionnée dans les sources. Comme nous le verrons plus loin, il s'agit probablement d'une émanation de Xochiquetzal, "Fleur-Plume précieuse", la déesse des arts, de la jeunesse et du plaisir sexuel.

(9) Tezcatlipoca, "Miroir-Fumant", est un dieu aux multiples facettes. Il était le dieu des souverains, des guerriers et des sorciers. Dans les mythes, il apparaît comme l'ennemi attitré de Quetzalcoatl. Les manuscrits pictographiques le représentent fréquemment amputé d'une jambe qui lui a été arrachée par le Monstre de la Terre. 


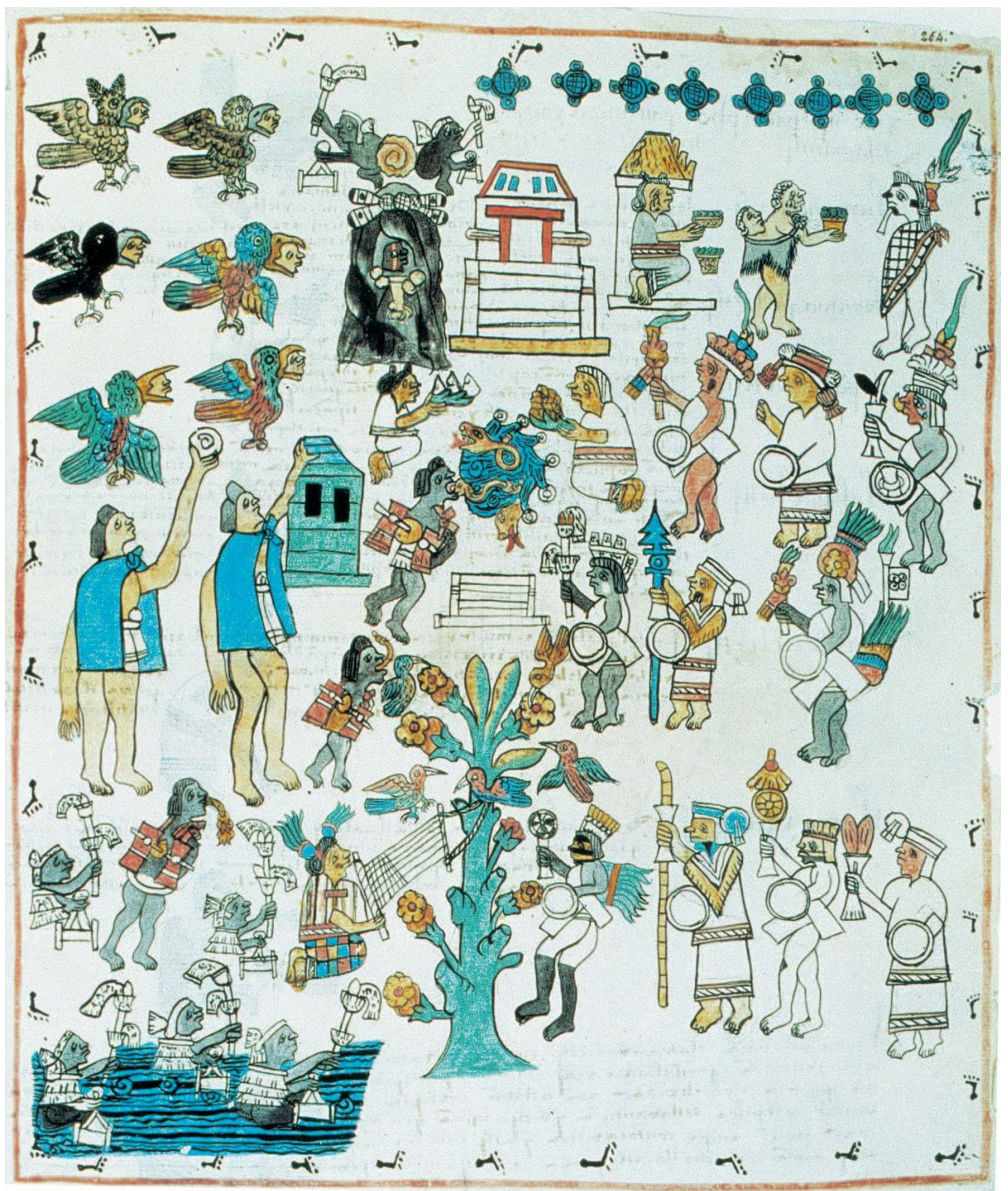

Illustration 1. La fête Atamalcualiztli (SAHAGÚN, Historia General de las cosas de Nueva España, Primeros Memoriales, fol $\left.254 \mathrm{r}^{\circ}\right)$. Codex de Madrid. Bibliothèque du Palais Royal, Madrid. 
amène à considérer Xochiquetzal et Ixnextli comme deux figures d'une même divinité. Les puissances divines mexicaines se caractérisent en effet par leur caractère polymorphe, leur capacité à prendre plusieurs formes et à se voir attribuer à ce titre une pluralité de dénominations. Il ne serait pas étonnant que Xochiquetzal ait changé son nom en Ixnextli une fois la faute commise. Le nom Xochiquetzal se rapporterait à la déesse considérée sous son aspect de "séductrice", celui d'Ixnextli exprimerait son statut de "pécheresse". Tous les éléments composant ce dessin illustrent à l'évidence la faute originelle commise au Tamoanchan. Au centre, l'arbre du Tamoanchan indique le lieu où la faute a été commise. Les fleurs qu'il porte rappellent une autre étymologie utilisée à propos du Tamoanchan, Xochitliccacan, "l'Endroit où se dressent les fleurs", mais elles évoquent également la sexualité féminine car la fleur est fréquemment utilisée dans la poésie nahua comme une métaphore du sexe féminin. Qui plus est, Xochiquetzal est connue pour être la déesse de la beauté et du plaisir sexuel (10). Mais si elle est à ce titre la patronne des auianime, les courtisanes qui offrent leurs charmes aux guerriers, elle n'en est pas moins la divinité présidant aux travaux artistiques, le tissage en particulier. C'est précisément le cas sur le dessin des Primeros Memoriales où l'on observe Xochiquetzal en train de tisser. Nous savons par ailleurs que le tissage était considéré par les Nahua comme une image de l'acte sexuel. Voici ce que rapporte Sahagún à ce propos :

«Ils disaient que les femmes tisserandes étaient quasiment toutes folles de leur corps $\mathrm{du}$ fait qu'elles tenaient l'origine du tissage de Xochiquetzal, laquelle les trompait, et que cette déesse leur occasionnait également la gale, des pustules incurables ainsi que d'autres maladies contagieuses. » (Sahagún, 1975, p. 225)

Un autre témoignage semble confirmer le rôle coupable de Tezcatlipoca en le désignant comme le séducteur de Xochiquetzal au Tamoanchan (Muñoz Camargo, 1982, p. 155). Cette association de Tezcatlipoca avec la tromperie et la faute à caractère sexuel semble être un trait récurrent de son caractère. En effet, selon un autre mythe célèbre relatant la geste de Quetzalcoatl, le célèbre dieu des Toltèques est vaincu par les maléfices de Tezcatlipoca. Non seulement ce dernier parvient à énivrer Quetzalcoatl, mais il l'amène également à avoir des relations coupables avec sa propre sœur, Quetzalpetlatl (Anales de Cuauhtitlán, 1992 : fols. 5 et 6 ; voir également une autre version de cette histoire in Sahagún, 1906, CMRP : fols. $139 \mathrm{r}^{\circ}$ à $\left.141 \mathrm{v}^{0}\right)$.

Ainsi, il ressort bien que la fête Atamalcualiztli, au-delà du jeûne observé pour aider la régénération des subsistances, celle du maïs en particulier, est aussi et surtout la commémoration de cette faute originelle commise par les dieux au

(10) Nous avons retrouvé dans d'autres sources un récit attestant le caractère licencieux de Xochiquetzal. Selon cette histoire, un homme dénommé Yappan décida de s'attirer la bienveillance des dieux en allant faire pénitence au sommet d'une pierre, sous la surveillance du dieu Yaotl, un autre nom de Tezcatlipoca. Mais un jour, Xochiquetzal rejoignit Yappan sur sa pierre et le séduisit. C'est alors que Yaotl, témoin indigné de cette scène, décapita Yappan et le transforma en scorpion (RUIZ DE ALARCón, 1948-1952, pp. 176-180, et SERNA, 1948-1952, pp. 226-229, 294-296). Or, la conjuration utilisée par les anciens Mexicains pour guérir une piqûre de scorpion était supposée émaner de la bouche de Piltzintecuhtli qui, sous l'apparence d'un cerf appelé Chicome-Xochitl, exhortait le mal identifié à Yappan à s'enfuir en rappelant à ce dernier sa relation coupable avec Xochiquetzal. Si la blessure se révélait d'une gravité particulière, c'est Xochiquetzal elle-même qui était censée parler par la voix du guérisseur. Elle rappelait à Yappan leur liaison illégitime et le faisait succomber à nouveau à ses charmes. 
Tamoanchan. Si l'on sait qu'une des conséquences de la faute sexuelle a été la naissance de Centeotl, le jeune dieu du maïs, il apparaît clairement que le repos accordé au maïs durant le jeûne prend tout son sens lorsqu'on le relie à la transgression de l'interdit (11).

Il est intéressant de confronter les sources que nous venons d'évoquer à propos d'Atamalcualiztli à un hymne sacré, ou teocuicatl, chanté à l'occasion de cette fête. Ce cantique fait partie d'un manuscrit en langue nahuatl provenant du travail de collecte réalisé vers le milieu du $\mathrm{XVI}^{\mathrm{e}}$ siècle par les informateurs indigènes du religieux Fray Bernardino de Sahagún. En préalable à notre commentaire, voici la transcription et la traduction que nous proposons de cet hymne :

Izcatqui y(n) cuicatl (PM: fol. $\left.279 \mathrm{r}^{\circ}\right)$

chicuexiuhtica mevaya iniq $(a) c$

atamal qualoya.

Xochitl noyollo cuepontimanja : ye tlaco

yoalle, oaya, oovayaye.

Yecoc ye tona(n) yecoc, yeteutl tlaçolteutla

oaya oovayaye.

Otlacatqui çenteutl tamiyoanicha(n) nj

xochitlicacanj. çey xochitlj yanta

la, yantata, ayyao, ayyave tilili

yao ayiave. oayyave.

Otlacatqui centeutl, atl, yayavicanj

tlaca pilla chivaloya chalchimichva

ca(n), yyao, yantala, yantanta a

yyao, ayyave, tilili yao, ayyave

oayyave.

Oyatlatonazqui tlavizcallevaya inan tlachi (ibid. : fol. $279 \mathrm{v}^{\circ}$ )

chinaya nepapa(n) quechol, xochitlacaca yya(n)

tala yantata, ayyao, ayyave, tilili yao

ayyave oayyave

Tlalpa(n) timoquetzca, tianquiz navaquj a

nitlacatla niquetzalcoatla yyantala ya(n)

tanta, ayyao, ayyave, tilili yao, ayya

ve oayyave.

Maya aviallo xochinquavitl itlanj

nepapa(n) quechollj maya in quechollj

xicaquiya tlatoaya ytoteuh xicaq(ui)

ya tlatoaya yquechol amach yeva

tomjcauh tlapitza amach yeva(n) tlacal

vaz. ovao.

Aye oho. yyayya çaniquiyecavizca

noxocha tonacaxochitlj yeizquixo

chitla, xochitlicaca. yyaa.

(11) Pour Michel Graulich également (1987, pp. 64-65), le Tamoanchan fut le théâtre de la transgression par des dieux d'un interdit sexuel qui justifia leur expulsion de ce lieu par le couple créateur que le Codex Telleriano-Remensis désigne sous les noms de Tonacatecuhtli et Tonacacihuat (1964-1967, pl. XXIII). 
ARCHIVES DE SCIENCES SOCIALES DES RELIGIONS

Ollama, ollama vive xolutl nava lachco, ollama xolutl. chalchive catl xiquitta mach. oyamoteca piltzi(n) tecutlj yoa(n)cha(n), yoancha(n)

Piltzintle piltzintle toçivitica timo potonja tlachco timotlallj yoancha(n) yoancha(n)

Oztomecatla yyave oztomecatla xochi (ibid. : fol. $280 \mathrm{r}^{\circ}$ ) quetzal quimama ontlatoa cholola ayye ayyo. oyemavinoyol, oyemaviltab noyol, aoya yecoc centeutl. mativia obispo, oztomecatl chacalhoa xiuh nacochtla yteamic ximaquiztla yteamico. ayye ayyo.

Cochina cochina cocochi yenicma ololo nicanj yecivatl nicochina yyeo ovayeo, yho, yya yya.

Voici le chant (que l'on entonnait) lorsque huit années s'étaient écoulées, quand des tamalli (cuites) à l'eau étaient mangées.

Mon cœur est une fleur qui s'est ouverte.

Elle, Tlaco, la Maîtresse de la nuit, oaya oouayaye.

Elle est arrivée, notre Mère,

elle est arrivée, la déesse Tlazolteotl, oaya oonayaye.

Centeotl est né au Tamoanchan, à l'Endroit où se dressent les fleurs, (un jour) Un-Fleur,

yantala yantata, ayyao ayyaue,

tilili, yao ayyane oayyaue.

Centeotl est né dans la Contrée de l'eau et de la brume, à l'Endroit où sont faits les enfants des hommes, au Pays des maîtres des poissons de jade, yyao, yantala yantanta, ayyao ayyaue, tilili, yao ayyaue oayyaue.

Déjà le soleil va briller, il commence à faire jour, des essaims d'oiseaux spatules aspirent l'eau à l'Endroit où se dressent les fleurs, yya(n)tala yantata, ayyao ayyaue, tilili, yao ayyane oayyane.

Tu foules le sol près de la place du marché. Ah! Je suis le seigneur, je suis Quetzalcoatl, yyantala ya(n)tanta, ayyao ayyaue, tilili, yao ayyaue oayyaue.

Qu'ils soient réjouis près de l'Arbre fleuri, les essaims d'oiseaux spatules.

Écoute-le chanter, l'oiseau spatule.

Toi, notre dieu, écoute-le chanter, l'oiseau spatule.

Est-ce que ce ne sont pas eux, nos morts, qui soufflent? Est-ce que ce ne sont pas eux qui tirent à la sarbacane? Ouao. 


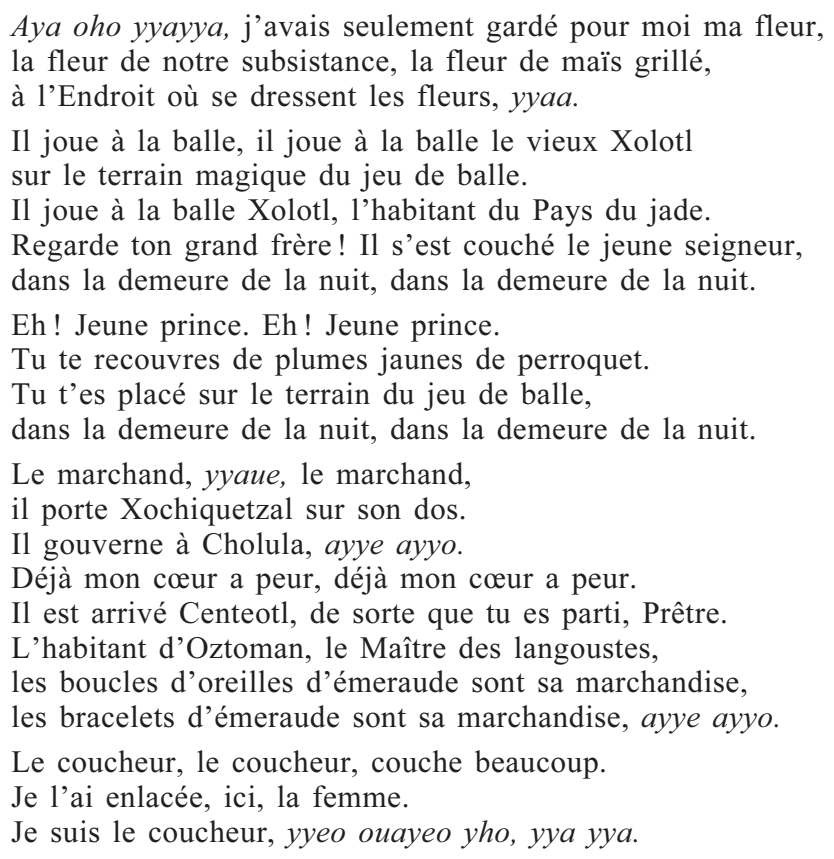

Xochitl noyollo cuepontimania, "mon cœur est une fleur qui s'est ouverte." Curieusement, cet hymne qui du fait de sa nature hiératique aurait dû débuter par une invocation respectueuse aux dieux ou par une adresse venant d'une de ces divinités, s'engage au contraire à la façon de chants lyriques tels que les xopancuicatl, "chants de printemps", ou les icnocuicatl, "chants de tristesse", dans lesquels une voix individuelle s'élève en épanchant son cœur. Mais très vite, une fois ce préambule récité, la collectivité des fidèles est introduite dans le monde des dieux qui vient se substituer à celui des hommes.

Dans cet hymne, le monde divin apparaît structuré en deux espaces-temps évoqués successivement : tout d'abord, le Tamoanchan et le lever du jour, ensuite l'inframonde et la nuit.

\section{Les évocations multiples du Tamoanchan}

Nous observons la richesse des métaphores et des expressions utilisées pour évoquer le Tamoanchan. Si l'on en croit les mythes, les récits et autres chants qui y font allusion, le Tamoanchan était une sorte de jardin extraordinaire dans lequel les dieux connaissaient un bonheur perpétuel jusqu'au jour où ils commirent la faute irrémédiable évoquée précédemment. Dans l'hymne sacré, ce lieu est successivement désigné sous les dénominations de "l'Endroit où se dressent les fleurs", "la Région de l'eau et de la brume", "l'Endroit où sont faits les enfants des hommes", 
"le Pays des maîtres des poissons de jade", "l'Arbre fleuri". Ces multiples appellations, loin de nous éclairer sur une localisation précise du Tamoanchan, conjuguent au contraire leurs effets pour estomper les contours de cet endroit mythique qui semble se diluer dans l'espace. Face à cette indétermination, Alfredo López Austin avance une définition très élargie du Tamoanchan. Selon cet auteur,

«Tamoanchan ne s'identifie pas seulement avec la partie la plus haute du cosmos, mais aussi avec le monde des morts, parce qu'il constitue tout le processus du merveilleux entrecroisement des courants céleste et terrestre, il est le lieu de la création, où tournent en s'entrelaçant les forces chaudes des neuf cieux et les froides des neuf niveaux de l'inframonde. Tamoanchan est le ciel et l'inframonde, c'est le lieu de la chaleur et du froid, du feu et de l'eau. » (López Austin, 1994, p. 93)

Le chercheur mexicain précise plus loin :

«Tamoanchan est l'axe du cosmos et l'ensemble des arbres cosmiques. C'est là qu'eut lieu le péché. Les dieux unirent les substances contraires, ils furent la cause du sexe, et avec lui de la création d'un autre espace, d'autres êtres, d'un autre temps : le monde de l'homme. Les dieux pécheurs furent punis pour leur action en étant exilés vers le royaume de la mort et la surface de la terre. Les dieux commencèrent un autre type d'existence: transformés, ils donnèrent naissance aux êtres de ce monde; mais dès lors, ils étaient contaminés par la mort qui est la conséquence du sexe. Leur vie devenait limitée dans le temps, limitée dans l'espace, limitée dans leurs perceptions. Ils avaient, en revanche, la possibilité de se reproduire.» (ibid., p. 101)

Le Tamoanchan, plus qu'un lieu bien déterminé, siège de puissances à caractère statique, apparaît selon la conception de López Austin comme un immense espace abritant les forces créatrices en mouvement.

Pour notre part, nous voulons voir dans le Tamoanchan l'endroit de la création originelle et le lieu à partir duquel l'humanité est régulièrement recréée grâce à l'acte sexuel. Au Tamoanchan, la transgression d'un interdit sexuel par les dieux entraîna une réaction en chaîne et le déclenchement du cycle de la vie et de la mort. Retenons de l'analyse de López Austin l'idée d'un cycle de la vie et de la mort applicable à la fois aux êtres et aux plantes domestiques, reflétant ce que l'auteur qualifie très justement d'archétype du cycle végétal (ibid., pp. 15-16 et 209). Puisque nous parlons de la création de l'humanité, il est intéressant de relever un passage de la Historia de los Mexicanos por sus pinturas selon lequel «ce fut au cours de la huitième année après le déluge que les dieux créèrent les hommes » (12) (Pomar, Zurita, 1941, p. 215). Cet intervalle de huit ans a probablement rapport avec celui régissant la célébration de la fête Atamalcualiztli.

Tlazolteotl apparaît au début du chant. Le fait que la déesse soit évoquée ici comme maîtresse de la nuit nous renvoie à sa qualité de septième Seigneur de la Nuit. Si elle est saluée comme Tlaco, "Celle du milieu", qui est le nom d'une des quatre émanations de Tlazolteotl lorsqu'elle est invoquée en tant qu'Ixcuina, littéralement "(Celle) qui prend quatre visages", elle est également appelée "notre mère", en référence à son pouvoir de donneuse de vie. Il n'est pas étonnant de la retrouver dans les représentations des manuscrits pictographiques en train de mettre

(12) Il s'agit d'une référence à la célèbre légende des "soleils". Selon ce mythe, quatre ères ou "soleils" précédèrent notre monde. Chacun de ces "soleils" prit fin de manière brutale. Le quatrième "soleil" appelé Atonatiuh, "Soleil d'eau", ou Chalchiuhtonatiuh, "Soleil de jade", fut détruit lors d'un déluge provoqué par Quetzalcoatl. 
au monde un enfant (Códice Borbónico, 1991 : pl. 13). Le nom Tlazolteotl signifie "Déesse de l'ordure", "Déesse du péché". C'est auprès d'elle que les Mexica sur le point de mourir venaient confesser leurs fautes et faire pénitence. Dans l'hymne, la venue de cette divinité marque selon nous le moment de la purification, mais également la reconnaissance de la faute. La faute, c'est la transgression de l'interdit sexuel commis par une déesse au Tamoanchan. La purification, quant à elle, est le préalable nécessaire à la venue au monde de l'enfant qui est précisément le fruit de cette faute. Ce nouveau-né n'est autre que Centeotl, le jeune dieu du maïs. Il semble qu'il faille distinguer deux temps dans la naissance de Centeotl. Tout d'abord, sa conception proprement dite qui se situerait "au Tamoanchan, à l'Endroit où se dressent les fleurs", "l'Arbre fleuri", au-dessus des cieux. Ensuite, le lieu de sa gestation, si l'on peut dire, qui se trouverait "dans la Contrée de l'eau et de la brume, à l'Endroit où sont faits les enfants des hommes, au Pays des mâ̂tres des poissons de jade". Cette cavité amniotique où s'élabore le mystère de la venue au monde n'est autre que l'inframonde considéré non pas sous l'aspect de l'endroit de la désintégration derrière lequel on a trop souvent coutume de le voir, mais comme le lieu où, au contact de l'eau, les germes de vie se chargent des forces de croissance nécessaires à leur apparition sur terre (López Austin, 1994, pp. 161-165 et 223-225). L'association de la naissance avec le monde nocturne se retrouve dans les invocations des sages-femmes qui, lors des accouchements, invoquaient Yoalticitl, "Guérisseuse Nocturne", et Yoaltecuhtli, "Seigneur de la Nuit", respectivement protecteurs de la santé et du sommeil des enfants. Yoalticitl était la déesse des bains de vapeur, appelés xochicaltzin, "Vénérable Maison Fleurie" (Sahagún, 1975, p. 374), à l'intérieur desquels les sages-femmes installaient les parturientes au moment de l'accouchement. Nous reviendrons plus loin sur le lien existant entre la naissance du dieu du maïs et l'inframonde.

Le fait qu'il soit question de la naissance de Centeotl pourrait expliquer la présence de Quetzalcoatl, si l'on veut se souvenir que les suppliques adressées à ce dernier tenaient une place particulièrement importante lors des naissances. Grâce à son statut de créateur, ce dieu permettait en effet aux êtres de voir le jour (ibid., pp. 388-390 et 398).

Le chant évoque ensuite le lever du jour. Il s'agit précisément ici du lever héliaque de Vénus. Michel Graulich, observant que l'hymne était chanté tous les huit ans, le précise en ajoutant : «Cinteotl, appelé aussi Itztlacoliuhqui, est également, en effet, l'Étoile du Matin, "la première lumière du monde» (13) (Graulich, 1987, p. 66).

Le passage du poème décrivant une nuée d'oiseaux spatules autour de l'arbre fleuri rappelle une scène rapportée par Durán relative à une représentation organisée en l'honneur de Xochiquetzal près du temple de Huitzilopochtli :

«Ils construisaient une maison de fleurs et façonnaient des arbres couverts de fleurs parfumées, et là, ils faisaient asseoir la déesse Xochiquetzal. Pendant qu'ils dansaient,

(13) À l'occasion de sa thèse, Mythes et rites des vingtaines du Mexique Central préhispanique, Michel Graulich est arrivé à la conclusion que les deux fêtes Atamalculiaztli et Xochilhuitl n'en faisaient qu'une, Atamalcualiztli étant selon lui "une amplification d'Ochpaniztli qui avait lieu tous les huit ans" (1979-1980, pp. 436). Cet auteur considère également Itztlacoliuhqui, "Obsidienne recourbée", comme une émanation de Centeotl. 
ARCHIVES DE SCIENCES SOCIALES DES RELIGIONS

des enfants descendaient, les uns déguisés en petits oiseaux, les autres en papillons, fort joliment parés de belles plumes vertes, bleues, rouges et jaunes. Ils escaladaient les arbres, allant de branche en branche, butinant la rosée de ces fleurs.

Puis arrivaient les dieux, chacun revêtu de ses parures, car ces indiens étaient habillés de la même façon que les dieux de leurs autels; ils venaient avec leur sarbacane à la main tirer sur les enfants déguisés en oiseaux qui se trouvaient dans les arbres. Enfin, apparaissait pour les recevoir la déesse des fleurs qui s'appelait Xochiquetzal, elle les prenait par la main et les faisait asseoir à côté d'elle, leur témoignant l'honneur et le respect que de tels dieux méritaient. Là, elle leur offrait des fleurs et de la fumée d'encens, puis faisait venir ses représentants pour les distraire.» (Durán, 1967 : I, p. 193)

Même si Durán ne précise pas à quelle fête se rattache cette manifestation, nous relevons sa forte ressemblance à la fois avec la scène évoquée dans le cantique et l'illustration des Primeros Memoriales. De plus, nous savons grâce au texte de ces mêmes Primeros Memoriales qu'une danse était exécutée lors de la fête Atamalcualiztli par des individus costumés et déguisés in uitzitzilli, papalutl, in xicotli, in çayoli, in tototl, temollj tecujtlaololo (Sahagún, 1905 PM : fol. 253 v.), «en oiseau-mouche, en papillon, en grosse abeille, en mouche, en oiseau, en scarabée, en scarabée rouleur de boule d'excrément». Sur la vignette illustrant ce texte, on observe en haut de l'image à gauche, de petits êtres déguisés en oiseaux-mouches. Ce passage du poème mettant en scène des oiseaux spatules est en quelque sorte la partie chantée du spectacle de danse en train de se dérouler. Le choix de représenter des animaux connaissant des métamorphoses tels les insectes, ou l'hibernation tels les oiseaux-mouches, autant d'images du renouveau de la nature et de son réveil, ne souligne que mieux la signification du nouveau cycle de huit ans qu'instaure Atamalcualiztli.

Il est plus que probable que le passage du chant qui nous occupe et les lignes de Durán que nous venons de citer se rapportent à cette danse évoquant le renouveau de la nature décrit par Durán et les Primeros Memoriales.

Arrivé à cet endroit du chant, nous nous trouvons en présence d'un passage fort énigmatique et sur lequel, malheureusement, les chercheurs qui nous ont précédé dans l'étude ont donné fort peu d'explications. Qui plus est, leurs interprétations diffèrent radicalement. Que peut bien vouloir dire cette phrase çan niquiyecauizca noxocha, "j'avais seulement gardé pour moi ma fleur", et plus particulièrement la curieuse expression niquiyecauizca? (14)

(14) SELER y voit le causatif du verbe eco (ou ehco), mais sans justifier grammaticalement la terminaison de ce verbe (1904, p. 1068). GARIBAY avance que nous sommes en présence du verbe "ehecavazuia, faire du vent à quelqu'un, éventer" (1958, p. 165), verbe que nous ne trouvons sous cette forme dans aucun dictionnaire. Même si l'on a présente à l'esprit la grande faculté de la langue nahuatl à construire des mots de par sa nature agglutinante, la construction de Garibay reste hypothétique. Dibble et Anderson traduisent par un futur: "j'apporterai” (SAHAGÚN, 1981, p. 212), or le verbe possède le suffixe $c a$ qui ne correspond pas à une terminaison de futur. Thelma Sullivan traduit "j'apporterai seulement mes fleurs" (SAHAGÚN, 1997, p. 146), probablement à partir du verbe ecauia. Enfin, une autre lecture pourrait être proposée si l'on veut reconnaître le verbe yecahuia: "se rincer (s'enlever le savon)" (KARTTUNEN, 1992, p. 336).

(15) Nous savons que dans la langue nahuatl le plus-que-parfait se forme sur le prétérit. Même si le prétérit donné par les dictionnaires de SimÉon et de Molina est ocaui, Thelma Sullivan a démontré qu'il est possible que certains verbes se terminant en ia ou ya puissent former plusieurs prétérits, dont un en ajoutant un $z$ à la fin $(1992$, p. 81). Si l'on considère que le verbe cauia peut former son prétérit de cette 
En ce qui nous concerne, nous proposons la traduction: “je l'(ma fleur) avais gardée pour moi" (15). Peut-être faut-il rechercher le sens de cette expression dans la faute originelle commise au Tamoanchan exprimée métaphoriquement par la cueillette d'une fleur défendue.

La fleur est désignée dans le chant par un binôme : tonacaxochitl ye izquixochitl, "la fleur de notre subsistance, la fleur de maïs grillé". Si ces termes désignent bien deux espèces de fleur, nul doute qu'il faut y voir ici un sens métaphorique car nous savons que nombre de poèmes évoquent le sexe de la femme avec le mot "fleur". Dans un poème connu sous le nom de "chant des femmes de Chalco", le sexe féminin est précisément appelé in quetzalizquixochitl, "la précieuse fleur de maïs grillé". Cette connotation sexuelle attachée à la fleur lèverait toute ambiguïté quant à l'allusion à la faute commise au Tamoanchan.

\section{Le terrain du jeu de balle, le monde nocturne et la naissance du Dieu Maïs}

Le nouvel univers évoqué par les deux strophes mettant en scène Xolotl et Piltzintecuhtli rompt nettement avec celui du Tamoanchan décrit auparavant, fait de soleil, de fleurs, d'oiseaux, de chants et de création. Là, nous entrons dans le domaine de la nuit où l'on voit le vieux Xolotl évoluer sur le terrain de l'inquiétant jeu de balle associé à l'inframonde (16). Dans la demeure de la nuit, sous la terre, va s'accomplir un mystère étonnant : le cycle de la germination. Paré de ses plumes précieuses, le jeune prince se couche pour accomplir l'acte de génération.

Si l'on en croit les mythes, c'est accompagné de son double, le chien Xolotl, que Quetzalcoatl est descendu sous terre, au Mictlan, récupérer les os des morts en vue de recréer l'humanité détruite. Mais Xolotl est également le dieu qui refusa de se sacrifier lors du premier lever de soleil en se transformant, entre autres, en double épi de maïs, et nous savons que le mot xolotl, à l'instar du mot coatl, renvoie à la notion de double, de gémellité.

(suite de la note 15)

manière, niquiyecauizca peut alors se décomposer de la façon suivante: ni-qui-ye-(o)cauiz-ca, c'est-à-dire article-complément d'objet direct-adverbe-prétérit-suffixe du plus-que-parfait, ce qui donne "je l' (ma fleur) avais gardée pour moi". Michel Graulich se demande si cette expression ne pourrait pas avoir rapport avec yecahuia : "se rince, s'enlève le savon" (communication personnelle). Il faudrait comprendre ici : laver une souillure.

(16) Selon la Crónica Mexicáyotl, lorsque les Mexica, au terme de leur longue errance, reçurent l'ordre de leur dieu de s'arrêter au pied d'un nopal pour fonder Tenochtitlan, ils construisirent à cet endroit désigné sous le nom d'Oztotempan, littéralement “À l'entrée de la caverne", un autel de terre et un terrain de jeu de balle (Tezozómoc, 1992, pp. 66-67). Nous retrouvons ici trois éléments essentiels de la cosmogonie mésoaméricaine présents dans le chant, à savoir l'arbre évoquant le monde céleste, la grotte symbolisant l'inframonde et le terrain du jeu de balle qui est le point de passage entre les deux mondes précédents.

(17) Le Popol Vuh est un livre rédigé en langue quiché vers le milieu du $\mathrm{XVI}^{\mathrm{e}}$ siècle par un lettré maya quiché. Ce texte relate successivement la création de la terre et des êtres vivants, la geste des jumeaux héroïques partis sous la terre défier les puissances du royaume de Xibalba, enfin l'histoire légendaire des dynasties quichés. 
Le mythe auquel se rapporte la fête Atamalcualiztli n'est pas sans rappeler le Popol Vuh des Maya (17). Selon cette histoire, deux jumeaux, Hun Hunahpu et Vucub Hunahpu, descendirent sous la terre défier les puissances maléfiques du royaume de Xibalba. Le combat se solda par la défaite des deux frères qui furent mis à mort. Pour commémorer leur victoire, les Seigneurs de Xibalba placèrent la tête décapitée de Hun Hunahpu entre les branches d'un arbre stérile. Aussitôt, l'arbre qui n'avait jamais donné de fruits jusqu'alors se couvrit de belles calebasses rondes parmi lesquelles on ne distingua plus la tête de Hun Hunahpu. Devant un tel prodige, les puissances du Royaume de la Mort décrétèrent sur le champ qu'il était interdit à quiconque de s'approcher de l'arbre. Malgré cette mise en garde, une jeune fille, Ixquic, poussée par la curiosité, vint au pied de l'arbre contempler les superbes fruits. Émerveillée par un tel spectacle, l'adolescente consentit à recevoir dans sa main la salive de la tête de Hun Hunahpu. En réalité, Ixquic venait d'être fécondée. Elle s'échappa de l'inframonde pour venir donner naissance sur terre à deux jumeaux, Hunahpu et Ixbalanque. Ces derniers, tout comme leur père et leur oncle par le passé, descendirent sous terre défier les seigneurs de Xibalba. Mais, contrairement à leurs aînés, grâce à leur ruse, Hunahpu et Ixbalanque parvinrent à déjouer les pièges des divinités du royaume des morts à l'issue d'une partie de jeu de balle. Un des motifs privilégiés de la poterie maya classique représente cette victoire (illustration 2) : on y voit les jumeaux hérö̈ques de part et d'autre de leur père émergeant d'une carapace de tortue. Une telle scène est interprétée comme la résurrection du Dieu Maïs sortant de la terre.

Le jeu de balle, un arbre près duquel une jeune femme transgresse un interdit sexuel, un mouvement cyclique entre la surface de la terre et le monde souterrain, la renaissance du maïs sont quelques-uns des traits communs les plus significatifs que l'on peut relever entre le mythe nahua commémoré lors de la fête Atamalcualiztli et le Popol Vuh des Maya (18).

Les deux dernières strophes du chant célèbrent l'union de Piltzintecuhtli et de Xochiquetzal (19) de laquelle naîtra Centeotl. Quant à l'explication du rôle de Quetzalcoatl, désigné ici sous les noms d'"habitant d'Oztoman" (20) et de "Maître des langoustes", nous n'avons pu que constater le désaccord entre les chercheurs (21) qui se sont attachés à analyser cette question, quand ce n'est pas leur désarroi. Les deux pronominations désignant Quetzalcoatl nous renvoient à l'inframonde en ce que ce dernier recouvre les forces obscures qui président à la venue au

(18) D'autres rapprochements pourraient être faits avec la mythologie maya où les jumeaux héroïques du Popol Vuh sont associés à Vénus. Chez les Aztèques, Tianquiztli, "le marché", désignait la constellation des Pléiades. D'autre part, Anthony Aveni a avancé 1'idée que la constellation des Gémeaux était appelée Citlallachtli, "le terrain du jeu de balle stellaire" (cité par FreIdEL, SCHELE et PARKER, 1993, p. 426). Ainsi, le chant d'Atamalcualiztli pourrait être lu également, à l'instar du Popol Vuh, sur un plan stellaire (pour d'autres développements mettant en évidence des similitudes entre cosmogonies aztèque et maya voir SAURIN, 1997 et 1999).

(19) Un autre hymne sacré, "le chant de Xochiquetzal", met en scène Piltzintecuhtli en train de chercher Xochiquetzal (sur le commentaire de ce chant, voir SAURIN, 1999, pp. 106-109).

(20) À juste titre, Hans Dietschy a relevé que le titre d'Oztomeca désignait les marchands et qu'une des cinq divinités de ces marchands s'appelait Cochimetl, "Coucheur" (1983, pp. 24-25), dans lequel on pourrait reconnaître le personnage évoqué à la fin du chant.

(21) Hans Dietschy assimile Quetzalcoatl à Piltzintecuhtli tandis que Michel GraUlich voit en cette dernière divinité une émanation de Tezcatlipoca (1987, pp. 66 ; 271). De son côté, VAN ZANTWIJK reconnaît Tezcatlipoca derrière Xolotl et identifie le soleil sous les traits de Piltzintecuhtli (1958, p. 85). 


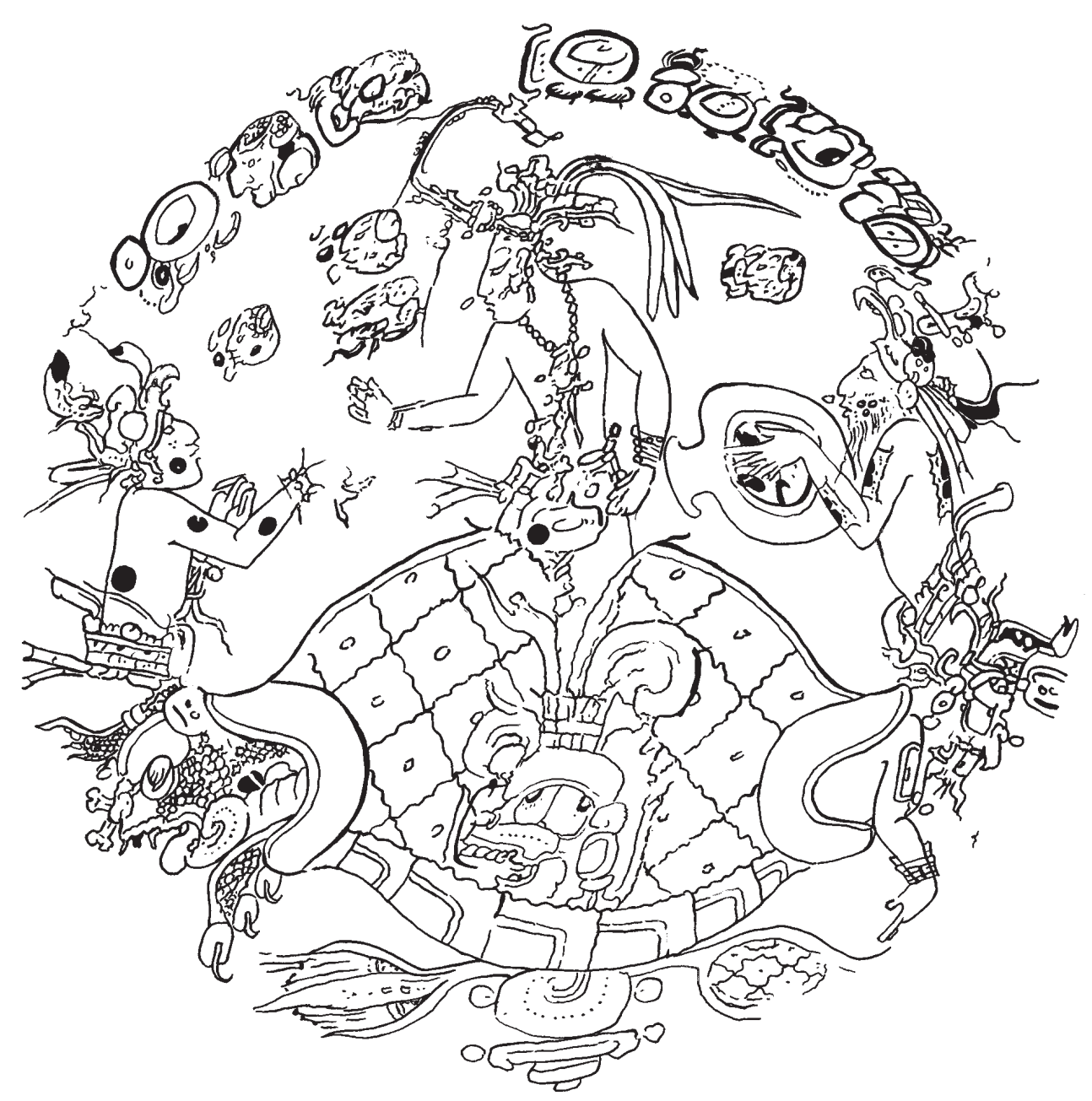

Illustration 2. Scène représentant la résurrection du dieu du maïs émergeant de la terre symbolisée par une carapace de tortue. Le dieu, Hun Hunahpu, est entouré de ses deux fils Hunahpu et Xbalanque (intérieur d'un bol maya en terre cuite, Classique tardif, dessin de l'auteur). 
monde. Oztotl, la caverne, évoque à la fois l'utérus et le lieu sous la terre où germent les graines. Quant aux langoustes, elles connotent un univers aqueux, amniotique et sont reliées également à l'idée de gestation.

L'union de Piltzintecuhtli et de Xochiquetzal est relatée à deux reprises dans l'Histoyre du Méchique. À propos d'un mythe de création ayant cours à Texcoco, il est écrit : «En ce temps mesme, y avoyt un aultre dieu, nomé pilciutentli, et sa femme se appelloyt Chuquiquecal, les quels avoynt ung fild nome Choquipili...» (Histoyre du Méchique, 1905: 30). Plus loin, à propos cette fois d'un mythe recueilli chez les gens de Chalco, nous avons une autre version plus détaillée :

«Le blai quils mangent se appelle maïz, fut faict de cette sorte : les dieux descendirent touts en une caverne, où ung dieu nomé Pieciutentli se estoyt couché avec une déesse nomée Choqujceli, de la quelle nacquist ung dieu, dict Ciutentl, le quel se mit de soubs la terre, et de ses cheveux sortit le coton, et de ung eouill une fort bonne semence quils mangent volountiers, nomée Sanctlhqez, de l'aultre un aultre, du nais ung aultre semence, nomée chia, qui est bonne à bouyre en temps de esté, des doigts sortit ung fruict nomé camotl qui est comme des naveaux fort bon fruict, des oungles aultre sorte de maïs large qui est le forment quils mangent à présent, et du reste du corps luy sortit beaucoup de aultres fruicts, les quels les hommes ceuillent et sement : et pour ce estoyt ce dieu aimé des aultres dieux e l'appelloint Tlacopili qui veult dire seigneur aimé.» (ibid., pp. 31-32)

$\mathrm{Au}$ vu de ces récits, la fin du chant s'éclaire. Une fois la pénitence terminée, une fois accompli le jeûne en souvenir de la faute originelle commise au Tamoanchan, l'union des dieux peut intervenir inaugurant, comme l'a fort bien vu Michel Graulich, la sexualité et la mort, la nourriture et les plantes cultivées, le lever de Vénus, l'Étoile du matin, la première lumière du monde et enfin la naissance de la terre (Graulich, 1987, p. 66).

Quetzalcoatl est décrit en train de porter Xochiquetzal sur son dos. On sait que chez les anciens Mexicains, lors du cérémonial du mariage, la promise était amenée à la maison de son futur époux de nuit par une "marieuse" qui la portait sur son dos (Sahagún, 1975, p. 365). Le Codex Mendoza nous offre la représentation de ce cérémonial (Codex Mendoza, 1984, pl. 61). Dans le chant, même si ce n'est pas une matrone qui porte la mariée mais Quetzalcoatl sous l'apparence d'un marchand, la référence à une union ne nous semble faire aucun doute (22).

Portant Xochiquetzal sur son dos, Quetzalcoatl est comparé à un marchand chargé de sa marchandise. Les xiuhnacochtli, les "boucles d'oreilles d'émeraude", les ximaquiztli, les "bracelets d'émeraude", sont à comprendre selon nous comme une désignation métaphorique de la belle déesse. D'autre part, les xiuhnacochtli pourraient également rappeler les ornements d'oreilles qu'arboraient les marchands revenus vainqueurs de leurs expéditions, et appelés quetzalcoyolnacochtli, "boucles d'oreilles aux grelots précieux".

La ville de Cholula (23), mentionnée dans le cantique, nous renvoie naturellement à Quetzalcoatl, le dieu tutélaire de cette cité laquelle était réputée pour être un

(22) Relevons toutefois que, selon certaines sources, c'est l'époux qui porte la femme. Dans l'Histoyre du Méchique, l'hymen de Quetzalcoatl et de Mayauel est décrit de la façon suivante : “... il esveilla la vierge, et luy dict : "je te viens quérir pour te mener au monde." A quoy elle accorda incontinent, et ainsi descendirent touts deux, luy la portant sur ses espaules..." (1905, p. 27).

(23) Cholula est une cité voisine de Tenochtitlan, célèbre pour ses édifices religieux et son marché. 
des lieux mythiques avec le Tamoanchan où, si l'on en croit Sahagún, les Mexica séjournèrent avant de fonder Tenochtitlan (Sahagún, 1975, pp.610-611). Nous savons également par Durán que le marché de Cholula était renommé pour son commerce de bijoux et de pierres précieuses (Durán, 1967 : I, p. 180).

Hans Dietschy, dans son analyse de ce chant, est parvenu à des conclusions sensiblement différentes des nôtres. Selon cet auteur,

"Quetzalcoatl apparaît terrestre, sur le marché, comme marchand-aventurier régnant à Cholula, sa ville renommée, ou encore comme marchand-prêtre porteur et coucheur; mais aussi, vu sa royauté, sa prêtrise et sa qualité de "Seigneur de ceux qui s'en vont", il apparaît vieux, là également. De plus, il semble vouloir se cacher : il a peur, il est un "fiancé honteux", rite confirmé comme institution, dans les cérémonies du mariage, par les quatre jours d'attente avant de "vraiment coucher ensemble". C'est un homme qui aimerait bien s'unir à la femme, mais qui n'ose pas - si ce n'est forcé par la coutume -, tout en sentant la jeune courtisane séduisante qui se cramponne à son dos. La femme Cinteotl céleste est devenue la Xochiquetzal terrestre, elle n'est enfin "rien qu'une femme". Et puis le coucheur fait son tour de main. Nous entrevoyons le motif mythique nord-américain bien connu de la femme céleste rendant visite à un homme terrestre...» (Dietschy, 1983, p. 27)

Pour notre part, même si nous ne nions pas que des motifs mythiques nord-américains puissent se retrouver dans un chant sacré des Aztèques, il nous a semblé préférable, dans le cadre de l'analyse de cet hymne, de nous référer, en priorité, aux sources mexicaines pour définir la place et le rôle des divinités concernées. Ainsi, nous n'avons pas reconnu Quetzalcoatl derrière Piltzintecuhtli et nous n'avons pas assimilé Centeotl à Xochiquetzal.

Il est intéressant de revenir sur l'aspect "marchand" attaché à Quetzalcoatl et sur les sources qui en font état.

C'est ainsi que Durán signale que les gens de Cholula avaient coutume de faire "une superbe et coûteuse fête à cette idole appelée Quetzalcoatl, lequel était le dieu des marchands" (Durán, 1967, I, p. 61). Un homme, censé représenter Quetzalcoatl, était acheté au marché aux esclaves pour être sacrifié le jour de la fête. Le dominicain, poursuivant le récit du détail des cérémonies, décrit ce qu'il intitule un intermède destiné à distraire les marchands et les seigneurs,

«mettant en scène un malade affligé d'une toux, faisant de grands gestes et des bouffonneries. Puis d'autres représentaient une mouche et un scarabée en apparaissant déguisés à la manière de ces animaux; l'un faisant le bourdonnement de la mouche en se posant sur sa chair, et l'autre la faisant fuir en lui disant mille sottises, et celui déguisé en scarabée se mettant dans l'ordure.» (ibid., p. 66)

La poursuite du récit de la fête par Durán est fort instructive pour le sujet qui nous occupe :

"Ce jour là, tout le pain était fait sans cuire le maïs avec la chaux, il était seulement cuit dans l'eau seule. De sorte qu'une fois le maïs cuit de cette façon dans l'eau seule, ils le moulaient et une fois moulu, ils délayaient cette pâte dans l'eau, en la gardant bien épaisse et ensuite la filtraient à l'aide de tissus fins. Après, ils prenaient cette pâte et la mettaient enveloppée dans des feuilles de maïs et la cuisaient dans des marmites et elle s'épaississait à l'intérieur de ces petites feuilles grâce au feu, et ils mangeaient seulement de ce pain et d'aucun autre. Ils appelaient ce pain dans la langue atamalli, ce qui signifie "pain (cuit) à l'eau seule", ce qui signifie à vrai dire pain sec, pétri avec de l'eau sans sel ni levure." (ibid., pp. 66-67) 
Une saynète mettant aux prises des individus déguisés en insectes, un jeûne avec des tamales cuites à l'eau, ne sont-ils pas les indices probants qu'il est question d'Atamacualiztli? Nous le pensons.

Mais comment expliquer dans le chant, le rang de tout premier plan tenu par les marchands, information absente des autres sources en langue nahuatl relatives à l'origine de cette fête. L'explication est à chercher, selon nous, soit dans le fait que ce chant puisse être une variante locale de célébration d'Atamalcualiztli ayant eu cours à Cholula, soit dans une évolution relativement tardive de la société mexicaine. Ainsi, au fur et à mesure du développement de l'empire grâce aux conquêtes militaires, le rôle des commerçants était devenu de plus en plus important. De telle sorte que Motecuhzoma en vint à leur accorder un certain nombre de faveurs, telles que le port d'insignes distinctives à l'image des guerriers et l'autorisation de sacrifier des esclaves. Il est parfaitement concevable qu'un tel changement dans les mœurs et les pratiques ait eu quelques conséquences dans la liturgie. Les références dans le chant à la ville de Cholula, à Quetzalcoatl, à un marchand et à sa marchandise pourraient être le signe de cette influence.

\section{Conclusion}

Les cérémonies accomplies à l'occasion de la fête Atamalcualiztli cristallisent l'essence du polythéisme mexica. La fête religieuse voit le divin tout envahir, devenir omniprésent. L'espace divin est recréé sur terre puisque l'on dresse près du Grand Temple «l'Arbre fleuri» du Tamoanchan. Au temps terrestre s'est substitué le temps divin, celui au cours duquel Xochiquetzal a commis la faute originelle. Les dieux sont présents "réellement", puisque leurs "images" revêtues de leurs costumes traditionnels s'appliquent à répéter les gestes fondateurs des rites. Ces divinités viennent donner à voir, selon les spécificités propres à chacune, leur activité inlassable entre Tamoanchan et Mictlan en vue de contribuer au maintien du cycle de vie, celui des hommes mais aussi celui des plantes.

La fête Atamalcualiztli vient rappeler que le Tamoanchan, même après la faute originelle, reste le lieu où se forme la vie. Selon la conception mésoaméricaine, le germe de vie doit suivre un processus bien particulier pour venir enfin au monde. À l'image du jeune enfant qui puise ses forces dans le ventre protecteur de sa mère avant de voir le jour, le maïs doit lui aussi séjourner dans l'environnement aqueux de l'inframonde, "la demeure de la nuit", avant de pouvoir s'élever fièrement vers le soleil et venir nourrir les hommes.

Mais derrière le caractère en apparence "domestique" d'Atamalcualiztli et la nécessité de laisser reposer la nourriture fatiguée, nous pouvons lire en filigrane le souvenir de la faute originelle commise au Tamoanchan. Le rite donne simultanément à entendre deux sens : un sens exotérique avec le repos de la nourriture et un sens de nature plus ésotérique avec le rappel de la faute commise au Tamoanchan. D'autre part, l'identification dans le chant de Quetzalcoatl, le dieu du vent annonciateur des pluies, à Oztomecatl, le "porteur", permet de reconnaître en lui un dieu qui porte sur son dos la jeune épousée Xochiquetzal dont l'union avec 
Piltzintecuhtli donnera naissance à Cinteotl, le maïs. Quetzalcoatl, souvenons-nous, a mis fin au quatrième soleil en provoquant un déluge. Or ici, en permettant l'union de Xochiquetzal et de Piltzintecuhtli, il agit comme un dieu créateur, plus particulièrement comme la puissance en charge de la reproduction et des naissances lesquelles interviennent précisément avec le cinquième soleil, Nahui Ollin, "Quatre-Mouvement". Quetzalcoatl apparaît ici plus que jamais comme une divinité ambivalente. D'un côté, il met fin au premier cycle de création, celui des dieux et des quatre premiers soleils. De l'autre, il contribue à la seconde création, celle des hommes appelés à vivre et à mourir dans ce qui sera la dernière ère, le cinquième soleil. D'autres sources présentent Quetzalcoatl comme un aide de Ometecuhtli et Omecihuatl, la paire divine présidant aux naissances (Sahagún, 1975, p. 389), soit comme le dieu créant lui-même l'humanité en versant le sang tiré de son sexe sur les os de la précédente humanité détruite (Leyenda de los Soles in Códice chimalpopoca, 1992, pp. 120-121).

Enfin, nous avons pu observer que les croyances en rapport avec le maïs à Mexico-Tenochtitlan se retrouvaient également dans le Popol Vuh des Maya, attestant ainsi la réalité et la vivacité de paradigmes communs aux populations de la Mésoamérique. Peut-être pourrait-on voir également une coincidence entre la régénération du maïs célébrée tous les huit ans chez les Nahua et l'association du maïs avec le chiffre huit chez les Maya (24).

Patrick SAURIN

Docteur en histoire

(24) Sur l'association du chiffre huit et du maïs chez les Maya, voir TAube (1989). 
ARCHIVES DE SCIENCES SOCIALES DES RELIGIONS

\section{BIBLIOGRAPHIE}

BRINTON Daniel, Rig Veda Americanus. Sacred Songs of the Ancient Mexicans, with a Gloss in Nahuatl, Philadelphia, Brinton's Library of Aboriginal American Literature ( $\left.\mathrm{n}^{\circ} \mathrm{VIII}^{\circ}\right), 1890$.

CARRASCO David, "Uttered from the Heart: Guilty Rhetoric Among the Aztecs », History of Religions, vol. 39, $\mathrm{n}^{\circ} 1,1999$, pp. 1-31.

Codex Mendoza, Commentaires de Kurt Ross, Fribourg, Liber, 1984.

Códice Borbónico. El libro del ciuacoatl, Introduction et explication de F. Anders, M. Jansen et L. Reyes García, México, Sociedad Estatal Quinto Centenario, Akademische Druck-und Verlagsanstalt, Fondo de Cultura Económica, 1991.

Códice Chimalpopoca. Anales de Cuauhtitlán y leyenda de los soles, Traduction de P. F. Velázquez, México, UNAM IIH, 1992.

Códice Telleriano-Remensis, in Lord KINGSBOROUGH, ed., Antigüedades de México, prologue de A. Yáñez, étude et interprétation de J. Corona Núñez, 4 vol., México, Secretaría de Hacienda y Crédito Publico, vol. 1, 1964-1967, pp. 151-338.

Códice Vaticanus A o Latino 3738 o Códice Rios, in Lord KINGSBOROUGH, ed., Antigüedades de México, prologue de A. Yáñez, étude et interprétation de J. Corona Núñez, 4 vol., México, Secretaría de Hacienda y Crédito Publico, vol. 3, 1964-1967, pp. 7-314,

DIETSCHY Hans, «La Fiancée Céleste et le Chaman Honteux Terrestre. Notes à propos d'un hymne mexicain », Société suisse des Américanistes, vol. 47, 1983, pp. 19-28.

DURÁN Fray Diego, Historia de las Indias de Nueva España e islas de la tierra firme, 2 vol., México, Porrúa, 1967.

FREIDEL David, SCHELE Linda, PARKER Joy, Maya Cosmos. Three Thousand Years on the Shaman's Path, New York, William Morrow \& Company, Inc, 1993.

GARIBAY K. Ángel María, «Relación breve de las fiestas de los dioses », Tlalocan, vol. II, nº 4, 1948, pp. 289-320.

GARIBAY K. Ángel María, Veinte himnos sacros de los nahuas, Édition, version et commentaire des teocuicatl par A. M. K. Garibay, México, UNAM IIH, 1958.

GRAULICH Michel, Mythes et rites des vingtaines du Mexique Central préhispanique, thèse soutenue à l’Université Libre de Bruxelles, 1979-1980.

GRAULICH Michel, Mythes et rituels du Mexique ancien préhispanique, Bruxelles, Académie Royale de Belgique, 1987.

Historia de los Mexicanos por sus pinturas (manuscrit anonyme de 1547), in J. B. POMAR, A. de ZURITA, eds., Relaciones de Texcoco y de la Nueva España, México, Chavez Hayhoe, 1941.

Histoyre du Méchique. Manuscrit français inédit du XVIe siècle, texte publié par É. DE JONGHE, Journal de la Société des Américanistes 2, 1905, pp. 1-41.

KARTTUNEN Frances, An Analytical Dictionary of Nahuatl, Norman, Oklahoma, University of Oklahoma Press, 1992.

LÓPEZ AUSTIN Alfredo, Cuerpo humano e ideología. Las concepciones de los antiguos nahuas, 2 vol., México, UNAM IIA, 1980.

LÓPEZ AUSTIN Alfredo, Tamoanchan y Tlalocan, México, Fondo de Cultura Económica, 1994.

MUÑOZ CAMARGO Diego, Historia de Tlaxcala, México, Chavero, 1892.

POMAR Juan Bautista, ZURITA Alonso de, Relaciones de Texcoco y de la Nueva España, México, Chavez Hayhoe, 1941.

Popol Vuh. Les Dieux les Héros et les Hommes de l'Ancien Guatémala d'après le Livre du Conseil, Traduction et commentaire de G. Raynaud, Paris, Maisonneuve, 1975.

RUIZ de ALARCÓN Hernando, «Tratado de Las supersticiones y costumbres gentílicas que oy viuen entre los indios naturales de esta nueua españa, escrito en México, año de 1629 », in J. de la SERNA et al., Tratado de las idolatrias, supersticiones, dioses, ritos, hechicerías y otras costumbres gentílicas de las razas aborígenes de México, note, commentaires et étude de F. del Paso y Troncoso, 2 vol., México, Ediciones Fuente Cultural, vol. 2, 1948-1952, pp. 17-180.

SAHAGÚN Fray Bernardino de, Códices Matritenses en lengua mexicana, vol. VI, cuaderno $2^{\circ}$, I. Primeros memoriales..., II. Memoriales con escolios..., Madrid, phototypie de Hauser et Menet, 1905. 
ATAMALCUALIZTLI OU À LA RECHERCHE DU TAMOANCHAN PERDU

SAHAGÚN Fray Bernardino de, Códices Matritense del Real Palacio, vol. VII, I. Memoriales en tres columnas..., II. Memoriales en español..., Madrid, éd. F. del Paso y Troncoso, phototypie de Hauser et Menet, 1906.

SAHAGÚN Fray Bernardino de, Historia General de las cosas de Nueva España, México, Porrúa, 1975.

SAHAGÚN Fray Bernardino de, Florentine Codex. General History of the Things of the New Spain, Book 2: The Ceremonies, (texte établi, traduit et annoté par A. J. O. Anderson et C. Dibble), The School of American Research no 14, part 3, Salt Lake City, University of Utah Press, 1981.

SAHAGÚN Fray Bernardino de, Primeros Memoriales, (Édition facsimilée, photographiée par F. Anders), Norman, University of Oklahoma Press, 1993.

SAHAGÚN Fray Bernardino de, Primeros Memoriales, (paléographie du texte nahuatl et traduction anglaise de Thelma Sullivan, complétée et revue par Arthur J. O. Anderson, Charles E. Dibble, Eloïse Quiñones Keber et Ruwet Waynes, Norman et Madrid), University of Oklahoma Press en coopération avec le Patrimonio Nacional et la Real Academía de la Historia, 1997.

SAURIN Patrick, «Le chant d'Ixcozauhqui, hymne sacré des anciens Mexicains », Revue de l'Histoire des Religions, tome 214, fascicule 4, 1997, pp. 415-429.

SAURIN Patrick, Teocuicatl. Chants sacrés des anciens Mexicains, Paris, Mémoires de 1'Institut d'ethnologie du Musée de l'Homme, Publications scientifiques du Muséum, 1999.

SELER Eduard, Die religiösen Gesänge der alten Mexikaner, in Gesammelte Abhandlungen zur Amerikanischen Sprach-und Alterthumskunde, (introduction, paléographie, version et commentaire des teocuicatl par E. Seler), Berlin, A. Asher \& Co, t. II, 1904, pp. 959-1107.

SERNA Jacinto de la, «Manual de ministros de indios para el conocimiento de sus idolatrías, y extirpación de ellas », in Jacinto de LA SERNA et al., Tratado de las idolatrías, supersticiones, dioses, ritos, hechicerías y otras costumbres gentílicas de las razas aborígenes de México (note, commentaires et étude de F. del Paso y Troncoso), 2 vol., México, Ediciones Fuente Cultural, vol. 1, 1948-1952, pp. 47-368.

SUllivan Thelma D., Compendio de la Gramática Náhuatl, México, UNAM, IIH, 1992.

TAUBE Karl, «The Classic Maya Maize God: A Reappraisal», in Merle GREENE ROBERTSON, Virginia M. FIELDS, eds., Fifth Palenque Round Table, 1983, San Francisco, The Pre-Colombian Art Research Institute, vol. VII, 1985, pp. 171-181.

TAUBE Karl, «The Maize Tamale in Classic Maya Diet, Epigraphy and Art», American Antiquity, vol. 54, $\mathrm{n}^{\mathrm{o}} 1,1989$, pp. 31-51.

TEZOZÓMOC D. Hernando Alvarado, Crónica Mexicana (précédée du Codex Ramirez), México, Porrúa, 1980.

TEZOZÓMOC D. Hernando Alvarado, Crónica Mexicáyotl, (traduction de A. León), México, UNAM IIH, 1992.

VAN ZANTWIJK R. A. M., «Aztec Hymns as the expression of the Mexican Philosophy of life », Internationales Archiv Für Ethnographie, vol. XLVIII, Leyde, E. J. Brill, 1958, pp. 67-118. 
ARCHIVES DE SCIENCES SOCIALES DES RELIGIONS

Résumé

Tous les huit ans, les Aztèques célébraient une fête étonnante appelée Atamalcualiztli. L'analyse développée ici, à partir de témoignages en langue nahuatl et de manuscrits pictographiques recueillis au XVI siècle, révèle que le jeûne observé à cette occasion obéissait à la nécessité de laisser reposer la nourriture mais venait également rappeler une faute irrémédiable commise par les dieux au Tamoanchan, une sorte de paradis originel. Enfin, le rapprochement d'un hymne sacré chanté lors de cette fête avec le Popol Vuh établit d'indiscutables convergences entre la pensée des Aztèques et celle des Maya. Dans les deux conceptions, le cycle du maïs est évoqué par un mythe construit sur un schème narratif identique relatant en particulier une faute sexuelle commise près d'un arbre et une partie de jeu de balle dans l'inframonde.

\section{Abstract}

The Aztecs used to celebrate an amazing festival every eight years, called Atamalcualiztli. Based on testimonies in the nahuatl language and on pictographic manuscripts found during the sixteenth century, this study reveals that the fasting ritual during this celebration was, first a means to let the food rest, and also a way to commemorate an irremediable fault committed by the Gods in the Tamoanchan, some kind of primitive heaven. In addition, if you bring together a sacred hymn the Aztecs used to sing during this ceremony and the Popol Vuh, some undeniable similarities between the Aztec and the Maya world view appear. In both conceptions, the life cycle of maize was evoked thanks to a myth based on the same narrative scheme : a sexual fault committed next to a tree and a ballgame in the underworld.

\section{Resumen}

Cada ocho años, los aztecas celebraban una fiesta sorprendente llamada Atamalcualiztli. El análisis desarrollado aquí, a partir de los testimonios en lengua nahuatl y de manuscritos pictográficos recogidos en el siglo XVI, revela que el ayuno observado en esta ocasión obedecía a la necesidad de dejar reposar el alimento, pero remitía también a una falta irremediable cometida por los dioses en el Tamoanchan, una suerte de paraiso original. Finalmente, el acercamiento de un himno sagrado cantado en esta fiesta con el Popol Vuh establece indiscutibles convergencias entre el pensamiento de los aztecas y el de los mayas. En las dos concepciones, el ciclo del maíz es evocado por un mito construido sobre un esquema narrativo idéntico, que relata en particular una falta sexual cometida cerca de un árbol y una parte de juego de pelota en el inframundo. 